\title{
Study on Consumers' Satisfaction Degree and Influencing Factors of Online Shopping for Agricultural Products
}

\author{
Huang Jinhong \\ Wuhan Technology and Business University
Wuhan, China
e-mail: 30157704@qq.com
}

Xu Wei

Wuhan Technology and Business University

Wuhan, China

e-mail: 16661021@qq.com

\author{
Wei Hua \\ Wuhan Technology and Business University \\ Wuhan, China \\ e-mail: 344166747@qq.com \\ Wan Hui \\ Wuhan Technology and Business University \\ Wuhan, China \\ e-mail: 108181539@qq.com
}

\begin{abstract}
Shopping for agricultural products on line becomes a new form of consumer's consumption in China. Consumers' satisfaction degree of online shopping for agricultural products directly affects the development of ecommerce of agricultural products. Centering on online agricultural products, referring to relevant literature, basing on survey data of Justeasy, and through statistical analysis this paper found out that consumption concept, products quality, service of website and logistics distribution are the main factors influencing consumer's online shopping intention and satisfaction. Finally, the paper gives some reasonable suggestions to improve consumers' satisfaction degree of online shopping for agricultural products. The government should actively promote the quality traceability system of agricultural products. Online retailers of agricultural products should step up publicity and cultivate consumers' online shopping concept; give reasonable and attractive prices; perfect website design and detail descriptions of goods to enhance attraction and convenience; optimize the distribution system to ensure timely delivery and quality security; and improve after-sales service.
\end{abstract}

Keywords-online shopping for agricultural products; satisfaction degree; influencing factors; Justeasy; quality traceability system

\section{INTRODUCTION}

In recent years, online shopping for agricultural products becomes a new form of consumer's consumption. By November 2013, the national agricultural e-commerce platform has been over 30 thousand, among which professional e-commerce platforms for agricultural products have reached 3,000. From 2012 to 2025, the demand of cold chain food in China will increase from 200 million tons to 450 million tons, with an annual compound growth rate of $18.8 \% .{ }^{[1]}$ Under the background where our government encourages developing agricultural products online trading, chained distribution and farmers' online stores, this area will also attract a large number of enterprises, retailers and e-commercial businessmen in the next three to five years.
In the developing stage of agricultural e-commerce, due to many problems of online trade, trade disputes have frequently occurred. Consumers know few about online agricultural products and lack of confidence, so customer' satisfaction degree of online purchase of agricultural products is usually much lower. The plight of improving customers' loyalty is faced with at the same time. Research on consumers' satisfaction degree of online shopping for agricultural products and its influencing factors is of great significance.

\section{CONSUMERS' SATISFACTION DEGREE AND RELATED RESEARCHES}

American marketing master Philip Kotler defined customer satisfaction as: customer satisfaction is the feeling state formed after one compare the perceived effect or results of the product or service with his expectations ${ }^{[2]}$.

Economics theory uses consumer surplus value to explain the customer satisfaction. The balance margin between the total values of the product or service and the total cost consumers paid, namely the customer delivered value. The consumer can produce satisfaction if the customer delivered value is positive. The greater customer delivered value makes the higher consumer satisfaction degree. The consumer may produce dissatisfaction if the customer delivered value is negative to the contrary.

At present, scholars have researched the major factors of online shopping satisfaction from main categories, such as the value of product itself, service attitude, logistics efficiency, credibility and reputation, etc. Existing researches show that factors such as consumers' individual characteristics, attitudes towards online shopping, online shopping experience, web shopping guide, service quality, product characteristics, and consumer trust influence whether consumers choose online shopping, which website to choose for online shopping and online shopping satisfaction ${ }^{[3]}$. 


\section{MAIN FORMS AND ADVANTAGES OF ONLINE SHOPPING FOR AGRICULTURAL PRODUCTS}

Agricultural products are not easy to save for their perishable nature and the technical requirement of logistics and storage of products is much higher, so it requests that the production, sales and transportation process of agricultural products achieve rapid circulation to ensure product quality and efficiency of transportation. ${ }^{[4]}$

There are two main forms of agricultural products consumers shopping on line. One is direct express delivery, in which consumers can choose online payment and pay on delivery. Secondly, enterprises set temporary locker in the community and consumers hold a locker key, the enterprises will distribute products consumers shopping to the village store content box within a specified time, and then the consumers pickup by themselves, and in this way online payment is allowed. ${ }^{[5]}$

The main advantages of shopping for agricultural products on line displays in: firstly, online shopping is more convenient and quick, which saves the shopping time. Secondly, online shopping is convenient for comparing prices of agricultural products, and selectivity is stronger. Thirdly, the seller provides more comprehensive descriptions of the goods and provides reasonable suggestions for consumers to choose and buy products. ${ }^{[6]}$

\section{ANALYSIS OF SATISFACTION DEGREE FOR ONLINE SHOPPING FOR AGRICULTURAL PRODUCTS - A CASE STUDY BASED ON JUSTEASY}

\section{A. Introduction of Justeasy}

Wuhan Justeasy Agriculture Science and Technology limited Company (www.justeasy.com.cn, Justeasy for short in the following) referred to the modern agriculture science and technology company built by Hongbo Group and Wuhan Industry and Commerce College with huge money, which a is a professional enterprise to supply fresh vegetables for urban residents based on the family supply of fresh agricultural products with modern circulation chains of agricultural products.

Justeasy integrates GPRS modem communication technology and Internet technology into an organic whole with B2C e-commerce platform as the core to build the agricultural products circulation platform. It adopts selfservice delivery logistics system, forms scientific and efficient processes of agricultural cultivation and harvest, sorting and processing, storage and distribution, and have already owns a agricultural industry of advanced operation mode by building a complete industrial chain. The company has developed more than 100 communities in Wuhan, and has more than 30,000 members now.

\section{B. Credit Evaluation Result of Justeasy}

According to the credit evaluation system on just easy website, among the total of more than 1,820,000 evaluations, there are 1,771,562 for praise, 29,562 for medium evaluation, and 15314 for bad evaluation, with a positive rate of $97.3 \%$. Although from the favorable rate, just easy has generally won most of the buyers' satisfaction, more than 40 thousand medium and negative assessments at the same time also reflects unsatisfactory exists in consumers' online shopping process.
Bad evaluations can directly show factors of consumers' dissatisfaction of online shopping, so the author takes evaluations and assessments for sampling according to certain way of culling from the assessment system. Samples mainly contain bad evaluations and a few medium evaluations, with which the author finds factors influencing consumers' satisfaction from bad evaluations and supplement the content from medium evaluations. Finally, classify contents of consumers' assessments and find out the reasons of consumer dissatisfaction from the selected 4,000 samples. The analysis results is that the main reasons of discontent impacting consumers in the process of shopping for agricultural products on line: quality problems of the product itself, insufficiency of after-sales service, the problem of logistics that can't meet consumer demand, discrepancy between the physical commodities and description of merchants and mistake in delivering goods, as results in table I .

TABLE I. CONSUMERS` DISCONTENT REASONS IN JUSTEASY CREDIT EVALUATION SYSTEM

\begin{tabular}{|c|c|c|c|c|c|}
\hline Reasons & $\begin{array}{c}\text { Product } \\
\text { quality }\end{array}$ & $\begin{array}{c}\text { Discrepancy } \\
\text { with } \\
\text { description }\end{array}$ & $\begin{array}{c}\text { Logistics } \\
\text { problem }\end{array}$ & $\begin{array}{c}\text { After- } \\
\text { sales } \\
\text { service }\end{array}$ & Others \\
\hline Number & 1320 & 690 & 824 & 1060 & 106 \\
\hline Rate & $33 \%$ & $17.3 \%$ & $20.6 \%$ & $26.5 \%$ & $2.6 \%$ \\
\hline
\end{tabular}

Through more detailed analysis on the evaluations, the author finds that reasons affecting the consumer satisfaction cover many aspects. According to the frequency that detailed factors appear, the different degrees of influence on satisfaction can be analyzed: the more frequent occurrence explains its impact on consumer online shopping satisfaction is bigger, as the statistical analysis results shown in table II.

TABLE II. RANK OF FACTORS INFLUENCING CONSUMERS' SATISFACTION OF ONLINE SHOPPING

\begin{tabular}{|c|c|}
\hline Rank & Influencing factors \\
\hline 1 & Poor product quality \\
\hline 2 & Forged and fake commodity \\
\hline 3 & Improper package and high price \\
\hline 4 & Pass the buck and poor attitude with problems \\
\hline 5 & Coldness of after-sales service \\
\hline 6 & Cheated ads and untrue description \\
\hline 7 & Dispute in sales return \\
\hline 8 & Delay delivery \\
\hline 9 & No timely notify when stock out \\
\hline 10 & Discrepancy between entity and picture \\
\hline 11 & Wrong choice for unreasonable description \\
\hline 12 & Discontent caused by buyers' subjective reason \\
\hline 13 & No check of buyers' request, and deliver goods at ease \\
\hline 14 & Give short weight, different net content described with \\
\hline 15 & reality \\
\hline 16 & No delivery or refund, leading to buyers' loss of foods \\
& and money \\
\hline 17 &
\end{tabular}

\section{Analysis and enlightenment of questionnaire survey}

In addition to the analysis of the existing customer evaluation data in Justeasy, the author also made a questionnaire survey with Justeasy, understanding consumers' perception of online shopping for agricultural products, and in-depth studying the influential factors of consumer satisfaction of online shopping for agricultural 
products. 268 copies of questionnaires were distributed and 213 questionnaires were recovered, of which 190 are effective questionnaires.

1) Reasons for consumers' choice to buy fresh agricultural products through the network

TABLE III. REASONS FOR CONSUMERS' CHOICE TO BUY AGRICULTURAL PRODUCTS ON LINE

\begin{tabular}{|c|c|c|c|c|c|}
\hline Reasons & $\begin{array}{c}\text { It's } \\
\text { convenient } \\
\text { to shop on } \\
\text { line due to } \\
\text { busy work }\end{array}$ & $\begin{array}{c}\text { Price on } \\
\text { line is } \\
\text { low }\end{array}$ & $\begin{array}{c}\text { Choose } \\
\text { products } \\
\text { with good } \\
\text { evaluation }\end{array}$ & $\begin{array}{c}\text { Good } \\
\text { image } \\
\text { and } \\
\text { various } \\
\text { kinds }\end{array}$ & $\begin{array}{c}\text { Home } \\
\text { delivery } \\
\text { service }\end{array}$ \\
\hline Number & 99 & 49 & 19 & 4 & 19 \\
\hline Rate & $52.1 \%$ & $25.8 \%$ & $10 \%$ & $2.1 \%$ & $10 \%$ \\
\hline
\end{tabular}

Table III shows, most people choose to buy agricultural products on line because of convenience and timesaving as well as its transparent and reasonable prices. Therefore, Justeasy must maintain the price advantage since it is effective way to keep the customers or the acquisition of new customers, and logistics and distribution in time is also necessary.

2) Analysis of related factors influencing consumers' shopping on line

TABLE IV. MAIN FACTORS INFLUENCING CONSUMERS' SHOPPING FOR AGRICULTURAL PRODUCTS ON LINE

\begin{tabular}{|c|c|c|c|c|}
\hline $\begin{array}{c}\text { Main } \\
\text { factors }\end{array}$ & Freshness & Price & Delivery in time & Brand \\
\hline Number & 122 & 34 & 30 & 4 \\
\hline Rate & $64.2 \%$ & $17.9 \%$ & $15.8 \%$ & $2.1 \%$ \\
\hline
\end{tabular}

We can see from table IV: when consumers decide to shop for agricultural products on line, customers first concern the freshness of agricultural products, followed by the price and delivery time. It also shows that the influencing factors of online shopping satisfaction of agricultural products include the quality of the product itself, the price and the efficiency of logistics.

3) Limited price ranges of shopping on line compared with common agricultural products

TABLE V. ACCEPTED PRICE RANGES OF SHOPPING FOR AGRICULTURAL PRODUCTS ON LINE

\begin{tabular}{|c|c|c|c|c|}
\hline $\begin{array}{c}\text { Price } \\
\text { ranges }\end{array}$ & Similar & $\begin{array}{c}\text { Increase by } \\
\mathbf{1 0 \% - 3 0 \%}\end{array}$ & $\begin{array}{c}\text { Increase by } \\
\mathbf{3 0 \% - 5 0 \%}\end{array}$ & $\begin{array}{c}\text { Increase } \\
\text { by more } \\
\text { than 50\% }\end{array}$ \\
\hline Number & 152 & 31 & 5 & 2 \\
\hline Rate & $80 \%$ & $16.3 \%$ & $2.6 \%$ & $1.1 \%$ \\
\hline
\end{tabular}

We can see from table $\mathrm{V}: 80 \%$ of the people can accept online shopping with roughly the same prices with agricultural products and $16.3 \%$ people can accept the online shopping with higher price by $10 \%-30 \%$. So, prices of online agricultural products should not be increased by $30 \%$ than ordinary agricultural products, otherwise, $96.3 \%$ people are not willing to accept.

4) Concerns of consumers' online shopping for fresh Agricultural products
TABLE VI. CONSUMERS' CONCERNS IN SHOPPING FOR ONLINE AGRICULTURAL PRODUCTS

\begin{tabular}{|c|c|c|c|c|c|c|}
\hline Concern & $\begin{array}{c}\text { Quality } \\
\text { and } \\
\text { safety }\end{array}$ & $\begin{array}{c}\text { Discrepancy } \\
\text { with } \\
\text { description }\end{array}$ & Logistics & $\begin{array}{c}\text { After- } \\
\text { sales } \\
\text { service }\end{array}$ & $\begin{array}{c}\text { Safety } \\
\text { of } \\
\text { online } \\
\text { payment }\end{array}$ & Others \\
\hline Number & 137 & 25 & 19 & 4 & 3 & 2 \\
\hline Rate & $72 \%$ & $13.2 \%$ & $10 \%$ & $2.1 \%$ & $1.6 \%$ & $1.1 \%$ \\
\hline
\end{tabular}

We can see from table VI: $72 \%$ customers concern about the safety of agricultural products in market, so safety of products is a great challenge for websites.

\section{RESULTS AND SUGGESTIONS}

\section{A. Main problems in the field of agricultural e- commerce}

1) Incomplete law systems of agricultural e-commerce

Because of the lack of the guarantee of legal system, incomplete rules and regulations and insufficient administrative interventions, agricultural products in circulation channels often appear illegal sales behaviors such as shoddy, counterfeit famous brand, which greatly reduces the consumer's purchase intention and satisfaction.

2) Logistics and after-sales service of agricultural products cannot meet consumers need

Because of the natural attributes of agricultural products, it has higher requirement on the refrigeration technology and transport channels in the process of storage and transportation. Enterprise lacks perfect logistics system, so consumers' satisfaction for the logistics is not high. ${ }^{[7]}$ At the same time, enterprises cannot response to reflected questions in time and solve problems in the first time to meet customers' requirements due to their imperfect after-sales service system.

\section{3) Traditional purchasing concepts of consumers}

Due to the characteristics of the market system, coupled with the merchant's insufficient propaganda, consumption concepts of most consumers are traditional. They know little about online shopping for agricultural products, and even doubt about it, let alone convenience of online shopping for agricultural products in daily life. ${ }^{[8]}$

4) High transportation cost of agricultural products

Agricultural products are perishable, seasonal, with low gross interest rate, and it is difficult to package, handling, transport and storage in the process of logistics. All kinds of agricultural products need various storage methods to store, which presents special and higher requirements for the transport, packaging and processing of such agricultural products, so managing agricultural products risks in logistics and costs high in transport.

\section{B. Feasible suggestions for increasing consumers' satisfaction of online shopping}

1) The government should establish the quality traceability system of agricultural products

The government should play the leading role as a main department, forming an effective coordination mechanism. Many restricting factors exist in the process of traceability system construction. Solving the low level of standardization of agricultural production, crossed regulatory functions of the government, the lack of effective coordination mechanisms and other issues is a 
solution to establish long-term effective trace system and improve the level of quality safety of agricultural products in China.

2) To ensure the quality of agricultural products on line

Since customers cannot see the products, touch the products when shopping on line, one cannot spot check products qualities including whether the appearance and picture are consistent, and whether the basic functions meet the requirements etc. As life food source of nutrition, agricultural products sites should first of all ensure the quality of products and improve the overall customers' satisfaction for a long-term development.

3) Improve cold chain logistics system

The putrescible property of agricultural products requires more stringently for storage and cold chain system, but the imperfect technology has brought the difficulty for the storage and transport of agricultural products, which also affects the consumers' online shopping satisfaction of agricultural products. Consumers are most concerned about the freshness of product itself, in order to ensure the attributes of agricultural product itself, they should reduce the time in the link of - order - distribution", maintain efficiency and pay more attention to quality to improve consumers satisfaction.

4) Descriptions of the goods should be true and detailed

The main ingredients, production date, capacity, origin and other basic information of commodity attribute cannot be missed. The website is responsible to offer a reasonable description of the merchandise, introduce specific method of using the product, and guide consumers to make the right choice.

\section{5) The price must be reasonable and attractive}

As a shared infrastructure, commodity prices on network are transparent, consumers can know all kinds of product prices through the mouse, therefore, a reasonable price is very important for the sale of goods, which can not only promote the sales of the products, but also can increase consumers' satisfaction. ${ }^{[9]}$

6) Perfect the system of online service and after-sales service

The main reason for online shopping for agricultural products is business for work or inconvenience for going out, so effective communication when consumer's demand exists can enhance consumer satisfaction and cultivate consumer's loyalty. Agricultural product sites should join dialog customer service, where online service personnel should response to consumer inquiries timely, providing fast and efficient service which is convenient for users to consult in the purchase of food, at the same time, make after-sale service perfect.

\section{7) Optimize website design}

The website style should meet the theme of health and green for agricultural products to give consumers a relaxed and natural feeling, stimulating the purchase desire and pleasure. Commercial navigation should be concise and reasonable in structure design. Clear navigation and keywords search can quickly lock goods that consumers need, saving consumers' time in browsing Webpage, which can also improve customer satisfaction. ${ }^{10]}$

\section{CONCLUSION}

In order to develop agricultural e-commerce well, it is not only need to certify products quality necessary, but also to build storage transportation and platform of selling online scientific and complete systems. Enterprises need put into more in technology. Besides, the development of agricultural e-commerce is indispensible in with the policy support and completed law systems from our country. Our country is in need to perfect the quality traceability system of agricultural products, encourage enterprises to engage in and at the same time offer some subsides and good policies for enterprises.

\section{REFERENCES}

[1] Anonymous. National agricultural e-commerce platforms have been more than 3 million in 2013. China Industry Research Network, 2014.

[2] Philip Kotler. Principles of marketing (Eleventh Edition), Tsinghua University press, 2007,pp.234-236.

[3] Liang Wenzhuo, Hou Yunxian, Ge Ran. Analysis of Characteristics of China's online shopping for agricultural products. The problem of agricultural economy, April 2012,pp.40 - 43.

[4] Chen Long, Chen Ye, Wei Fei. Logistics development status and countermeasures of fresh agricultural products of China. Modern agricultural science and technology, March 2011,pp.113-115.

[5] Guo Na, Liu Dongying. A comparative analysis of online trade mode of agricultural products. The problem of agricultural economy, March 2009,pp.75 - 80 .

[6] Liu Qi, Yuan Jinfeng, Wang Qian. A review of research on online shopping intention of agricultural products. Jiangsu Agricultural Sciences, April 2014, Volume 42,pp.401 - 403.

[7] Zha Rong, Yang Hongxiang. Agricultural products leading by third party logistics integrated supply chain management research. Anhui agricultural science, August 2011,pp.118-120.

[8] Liu Yang, Zhu Hui. Study on consumer behavior of modern ecommerce mode. China trade, May 2010,pp.133 - 134.

[9] Fang Xiaoyan, Jiang Ling. Study on the influence factors of online shopping satisfaction. Theory of Jiangsu, March 2012,pp.44 - 46.

[10] Ban Ran. Analysis of consumer behavior under the environment of Internet marketing. Chinese trade, January 2011,pp.52 - 53. 